\title{
Activation and Regeneration of Chinese Elements under the Cross-cultural Background Reflected by the Design of EXCEPTION de MIXMIND
}

\author{
Xuemei Gao \\ College of Information and Business \\ Zhongyuan University of Technology \\ Zhengzhou, Henan, China 450007
}

\begin{abstract}
Chinese elements" is a concept raised under the cross-cultural background. It is trusted with our expectation to regain cultural identity and dignity. In the field of fashion design, Chinese elements have developed as a global trend. However, there still exist great differences between China and foreign countries in their application. Centering on how to integrate Chinese elements into fashion design, this article attempts to perform a relatively systematical research and analysis by taking the design of EXCEPTION de MIXMIND as example, and it also summarizes the creation mode adopted by EXCEPTION de MIXMIND in activating and regenerating Chinese elements under the cross-cultural background. It is our sincere hope that this article could serve as an inspiration in further exploring the artistic creativity of Chinese elements in fashion design.
\end{abstract}

Keywords-Chinese elements; cross-cultural background; EXCEPTION de MIXMIND; activation; regeneration

\section{INTRODUCTION}

In recent years, China's comprehensive national power has strengthened and its international status has also risen. As a result, its exchanges with the rest of the world in economy, trade and culture become increasingly frequent. Under such circumstances, more and more people start to focus their attention on China especially Chinese culture. The successful holding of 2008 Olympic Games and 2010 World Expo makes Chinese culture even hotter. As a global fashion, "Chinese elements" has already been recognized universally, more so in the field of design particularly fashion design. Hence, under today's cross-cultural background, it turns to be a great subject in fashion design to display China's cultural identity and ability.

In this subject, "Chinese elements" appears as a key word. Featuring a long history of development and a profound and extensive nature, Chinese culture occupies an important position in the treasure house of world culture. Nevertheless, in the earlier epoch, China has suffered an imbalance between the development of economy and culture, particularly neglecting the inheritance and development of the traditional culture. In fact, in an early time, foreign designer has already discovered the valuable elements in our traditional culture and incorporated them into their designs. As a materialized presentation integrating modern design ideas, philosophic thinking, life style, scientific and technological achievements, clothing possesses significant intellectual merits and practical meaning in the study on Chinese elements and on both theories and practices of inheriting and developing Chinese elements in modern fashion design. The author considers that in the application of Chinese elements, a domestic women clothing brand EXCEPTION de MIXMIND shows typical case value.

\section{WHAT IS “CHINESE ELEMENTS”?}

Prior to discussing how to apply Chinese elements in fashion design under the cross-cultural background, it is indispensable to figure out the meaning of it firstly. Actually, since the concept "Chinese elements" came into people's sights, scholars and experts never cease trying to give interpretations of it among which the commonest way is to generalize the word "elements". For example, the famous designer Zhu Hailiang explains the term like this: the socalled Chinese elements must reflect Chinese culture and cognize Chinese spirit. It belongs exclusively to China. Apart from things of concrete form such as dragon, Yellow River, blue and white porcelain, it should also contains things of abstract and spiritual level which can reflect and represent the value orientation, custom and spiritual outlook of our working people. Modern and ancient stuff which can embody above-mentioned features can all be counted as Chinese elements. ${ }^{[1]}$ To fashion design under the crosscultural background, this explanation offers a better application environment for "Chinese elements".

However, in practical application, many people still hold partial understanding of "Chinese elements". As far as they are concerned, the presentation of Chinese culture is to decompose traditional culture as elements. For instance, some professional periodicals of design class explain Chinese elements like this : "What do Chinese elements contain? There are Chinese calligraphy, Chinese painting, Four Treasures of Study, inkstone, Chinese brush, rice paper, Chinese ink, seal cutting, paper-cut, kite, shadow play, dragon and phoenix patterns, Ruyi pattern, auspicious clouds pattern, chopsticks, antithetical couplet, door-god, moon cake, gold ingot, etc.. " ${ }^{[2]}$ Although these objects all occupy unique positions in China's history, it doesn't mean that we should extract them and play a collage game, not to mention 
copy or archaize. Considering that the wording of "Chinese elements" implies the design technique of "extractioncollage" in itself, it might be easy to cause misunderstanding concerning its application. However, if we identify "extraction-collage" as the approach to express Chinese culture, will there be any essential difference between it and Mr. Luxun's description in Fetchism? After all, the extensiveness and profoundness of Chinese culture can never be presented by the simple act of fetching.

\section{III. “CHINESE ELEMENTS” UNDER THE CROSS-CULTURAL CONTEXT}

\section{A. Partially "Sinicization"}

In 2007, under the premise of ensuring the west European court dress style, the designs launched by John Galliano take a partial application of Chinese elements, transcending the conventional sense of beauty (as shown in "Fig. 1"); In Chanel Paris-Shanghai Métiers D'Arts collection held on Huangpu River in Dec. 2009, the bamboo hat, the Red Army hat, and especially the three Chinese characters “香奈儿” (which means Chanel) crookedly printed in that yellow sweater all left us with deep impression. "Fig. 2" However, by today's standard, the formal experimental significance of those fashion works greatly exceed their significance in spreading Chinese culture's content. Under the cross-cultural background and driven by the strangeness towards foreign culture, western designers often merely focus their attention on parts in absorbing Chinese elements for reflecting "Chinoiserie" in their eyes. But as local designers, it will be far from enough in understanding Chinese culture's essence and manifesting its depth if we also identify designs of Chinese style simply as drawing dragons in clothes or nailing Chinese knotted buttons when applying Chinese and other national elements.

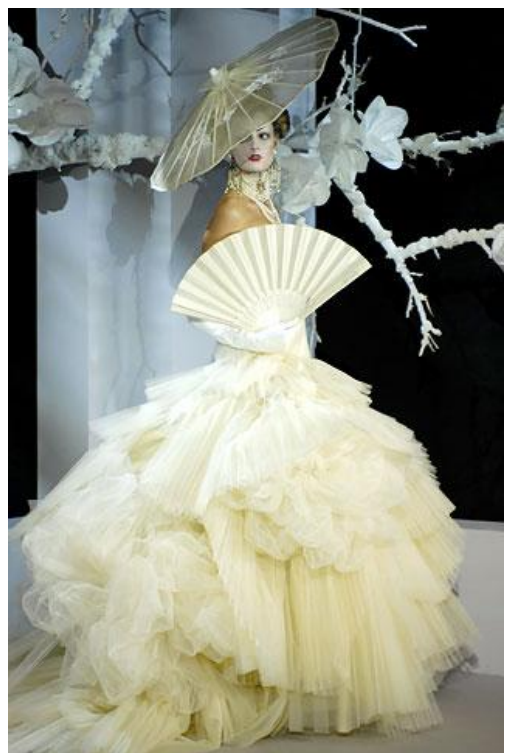

Fig. 1. Spring 2007 Couture Christian Dior

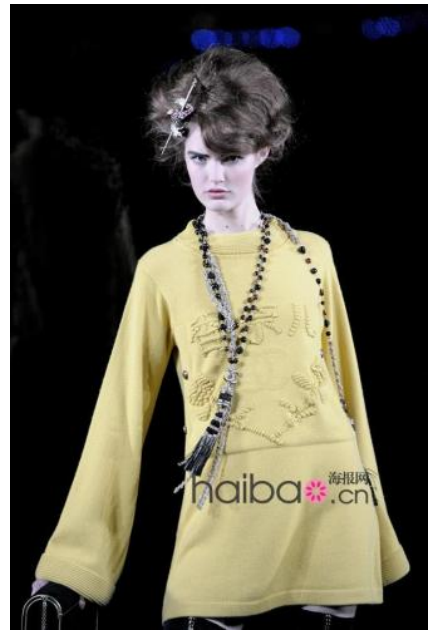

Fig. 2. The three Chinese characters “香奈儿” crookedly printed in the yellow sweater

\section{B. Completely "Sinicization"}

In the Paris Fashion Week 2011 Spring /Summer, a large amount of Chinese elements are integrated in the new collections of LV, attracting even more attention. During the entire show, what we see is an indiscriminate imitation of elements such as cheongsam, mandarin collar, Chinese knotted buttons, mandarin jacket and folding fan in accordance with the traditional pattern. For example, the placket is always decorated with Chinese knotted buttons; traditional patterns appear frequently; even cheongsam is matched with the updo. (as shown in "Fig. 3") We have to reconsider China's image in the eyes of those western designers.

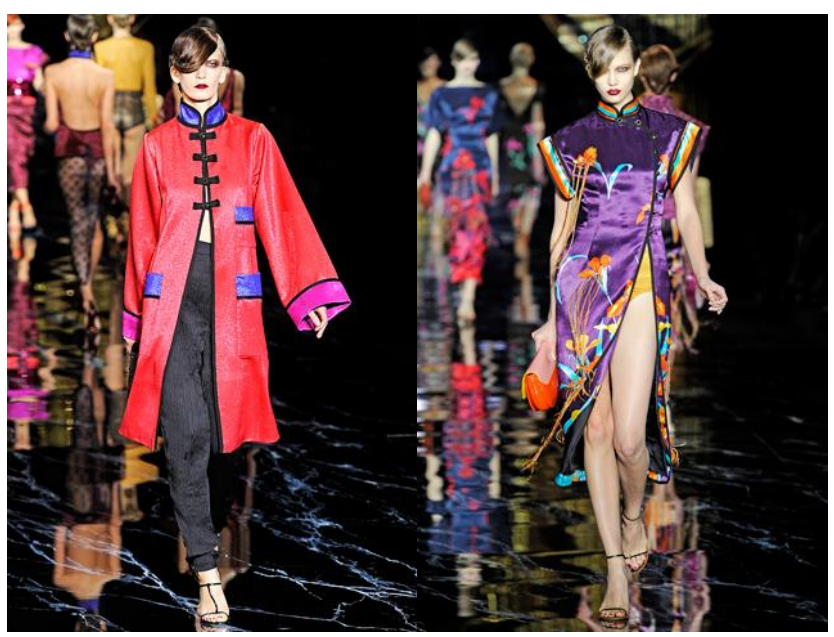

Fig. 3. LV Spring 2011 Ready-to-Wear

There exist great distinctions between the essence of Chinese and Western fashion culture. As a uni-source culture, Chinese fashion culture centers on the nature beneath forms and is strongly oriented socially, politically and ethically. As it always follows and adheres to the tradition, its demand for succession and continuity greatly overweigh that for variability and creativity. On the contrary, western fashion culture is a multi-source culture. It regards fashion as a 
special body art and focuses on the forms during its development. It possesses distinct characteristics of times and clear variation in style. Opposite to Chinese fashion culture, western fashion culture stresses variability and creativity more than succession and continuity. Therefore it turns to be another concept when observing Chinese culture in western perspective. Yet it is embarrassing that such design ideas are owned by many local designers. We need understand our own culture better and know which elements can be drawn to be combined with the modern trend. Taking into account the problems existing in applying Chinese elements, we still have a long journey to complete.

\section{C. "Convey the Spirit Via Forms"}

On the opening day of 2012 London Fashion Week, two Chinese native fashion brands EXCEPTION de MIXMIND and EVE CINA present jointly the "Mountain and Water. 2012 China Fashion Show". As the opening activity of the world top fashion week, this show gives a full expression of the essence of Chinese elements and becomes the most impressive cultural phenomenon during the fashion week (as "Fig. 4", "Fig. 5"). The subject of "Mountain and Water" is derived from the figure and landscape paintings of Song Dynasty which take little usage of luxuriant colors but outline the landscape with Chinese ink so as to convey spirits via forms. As one of the traditional Chinese painting techniques, "Convey the spirit via forms" demands that painter should catch the external typical features and also stress the inner spirit while creating an image. By doing so, the image created will be vividly shaped and achieve a harmony between spirit and form. By extracting the unique beauty of form reflected in the figure and landscape paintings of Song Dynasty from its original context and highlighting it as the element of clothing, EXCEPTION de MIXMIND attaches spirituality to the artistic touch of its clothing through both real and illusionary prospects and let people experience the humanistic feelings expressed by fashion designers from depth of their hearts in the meanwhile of pursuing interests and charms.

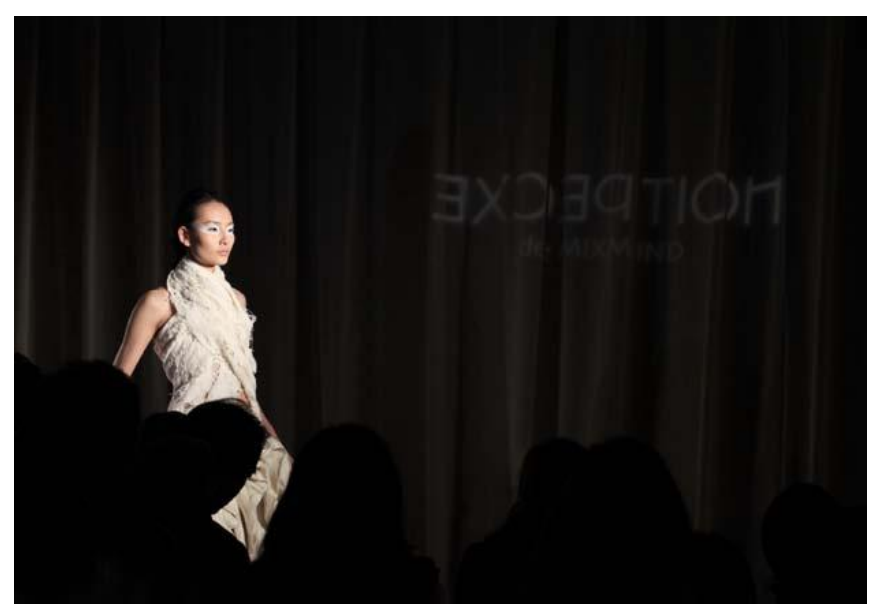

Fig. 4. Mountain and Water $\bullet 2012$ China Fashion Show

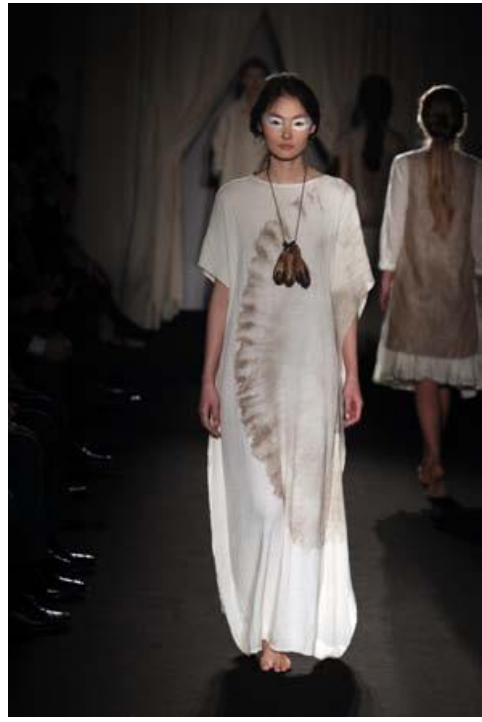

Fig. 5. Mountain and Water $\bullet 2012$ China Fashion Show

This expression of humanistic feelings once again reflects the pursuit of Chinese ancient literati towards artistic conception. Being romantic, this pursuit can be expressed by a hint of sentiment raised by the falling leaves or the gloom perceived from ink's dispersing layer upon layer in the water. Employing a simple and easy tailing approach, the designs of EXCEPTION de MIXMIND are monochrome-based and matched with natural textures. With their forms stressing the likeness in spirit rather than in appearance, EXCEPTION de MIXMIND focuses on pursuing a dynamic interest and charm and reflects a life attitude being simple, distinct and elegant as well as the natural, self-satisfied and free feelings advocated in Chinese aesthetics. It highly accords to the aesthetic realm of Chinese traditional paintings in that the "spirit likeness" is given priority over "shape likeness".

\section{ACTIVATION AND REgENERATION OF CHINESE ELEMENTS IN DESIGNS OF EXCEPTION DE MIXMIND}

In recent years, Chinese native designers start in succession to absorb nutrition from the precious cultural heritages left by the ancestors and carry out researches on fashion culture, artistic conception of works, philosophical thinking and other issues besides pure technical factors in fashion design. Among various native designer brands that spring up, EXCEPTION de MIXMIND enjoys a particularly prominent status. It was established by Mao Jihong and Ma Ke in Guangzhou, 2006. After being established, it sticks to the creative attitude of culture, aesthetics, innovation and low profile, successfully forging a contemporary life art of oriental philosophical style. Through EXCEPTION de MIXMIND, Ma Ke declares her brand culture of pursuing the spiritual essence and national self-confidence of Chinese people.

\section{A. How to "Activate"}

With time passing by, it is impossible also unnecessary for people to dress up in the past way. What deserves our 
study is the rich content of national culture carried by Chinese elements and how to activate it at present.

First, respect the traditional culture. It is not only the premise of activating Chinese elements but also the purpose must be reached in applying Chinese elements to modern fashion design. The aim of respecting traditional culture is to be better grounded on it and combine its element with the modern trend, especially contemporary scientific achievements, new materials, new processes and new means. Thus we are able to regenerate new forms of creative design and provide new "Chinese elements" to the world.

Second, completely understand the spirit of Chinese culture. "Reproducing Chinese elements can only yield materialized and concrete forms. What we really need to seize is the abstract spirit of national culture. It is a process of breaking and recreation. And our ultimate purpose is to provide modern clothes of both stylishness and cultural deposits". [3]

In the latest work (the collections of "land") of Ma Ke who is the designer of EXCEPTION de MIXMIND and USELESS, the costume modeling does not adopt the traditional method of the western world to perform a located three-dimensional shaping in terms of the concave-convex of human body. The costume has neither the parts such as the breast dart, the princess line and the armhole line, nor messiness and unconventionality of deconstruction frequently used in modern fashion design. The clothing structure almost completely succeeds to that of the traditional Chinese costume, giving people an impression of being true and simple. Only a tiered three-dimensional structure is applied to the collar opening and the hem, making the entire set of costume resemble a majestic mountain surrounded by the smooth surface of the lake. Taking the usage of handmade workmanship such as weaving, dyeing, trimming, cutting and sewing, the work highlights the philosophic thinking of EXCEPTION de MIXMIND on the spirits of Chinese culture, also the activation and application of Chinese elements at present.

Reviewing the design concepts of EXCEPTION de MIXMIND of each season, art director Ma Ke always tries to elevate these concepts from the design level to the spirit and the attitude level. Through these designs, we can find that the expectation of EXCEPTION de MIXMIND is not merely the design in forms, but also the aesthetic pursuit of reaching the cultural and spiritual level. By studying on the spirits of Chinese culture and in its efforts paid for their activation, EXCEPTION de MIXMIND not only provides numerous design inspirations, but also enriches the warehouse of formal expression. Moreover, it successfully integrates the philosophic thinking and Zen-like state of Chinese cultural spirits into its works, establishing and registering Chinese own national brand.

\section{B. How to "Regenerate"}

First, correspond with the international trend in design. "White Heart" is the first autumn and winter series of fashion collection launched by EXCEPTION de MIXMIND in the year 2009. This series does not involve the formalistic
Chinese elements which we are familiar with. Instead, it takes white as its main color scheme and employs clean profiles and lines. Thanks to the design of easiness and simplicity, the mind and body of the wearer are cultivated in the peace and purity brought by the clothing. In the meantime, the wearer can also sense Chinese spirits of elegance, intangibility, tranquility and forward-looking. The inspiration of 2009 EXCEPTION autumn clothing comes from the beauty of nature (which is implied by "Su" in Chinese language), thus producing the design under the principle of the Chinese character "Su": Su Xin-freedom and enough space; $\mathrm{Su}$ Shi-delight and relaxation inside out; $\mathrm{Su}$ $\mathrm{J}_{\mathrm{V}}$-concise shape and Zen spirit; Su Yan-simplicity and genuineness. It is in highly harmony with ecological ideas, environment friendly designs supported by green ideas, "simple and low-key" and "conservation-oriented" energy saving designs of the modern world trend in design.

Second, consider the consumption demand. In the same time of pursuing tastes, the dressing of modern people pays more and more intention to individuality. Clothes are required to be able to convey some national and cultural nature while expressing fashion characteristics. The application of Chinese elements in designs of EXCEPTION de MIXMIND is not revealed by the appearance: The embroidery abounds with interests; variations are played by the fine texture of fabrics; the special polishing on one hand motivates the inspiration of the wearers, on the other hand satisfies the need of expressing their life attitude and personality. Given the fact that clothing functions as the complex of culture, art, science and technology, it calls for our intensive study and serious execution and also the responsibility and obligation of our designers to figure out how to satisfy various demands of different consumers under the cross-cultural background, how to draw supports from the modern technical means and how to activate and regenerate "Chinese elements" while keeping pace with the world trend in design.

Today, the activation and generation of Chinese elements in designs of EXCEPTION de MIXMIND deserves our sincere study and reference. Sinicization means to activate through forms, contents and spirits. In short, the target of activation is the spirits of Chinese culture and the products of regeneration are forms in accordance with the contemporary needs, namely the new Chinese cultural fashion.

\section{CONCLUSION}

With the rapid rise of China's economy and the fast progress of modern culture, people start to ponder on clothing's real meaning to them. Besides the functions of covering body and keeping warm, it seems that clothes are carrying more and more power of culture and spirit. "In the evolution course of clothes, the physical and practical functions generally weaken while the significance of functions such as symbolizing, aesthetics and expressing incline to strengthen". ${ }^{[4]}$ The shift of the required function of clothes and the current cross-cultural context accelerate the changing of the design concept and the formal language of modern fashion design. In the field of design and creation, 
only on the condition that we hold devoted respect to the precious cultural heritage left by our ancestors, summarize the predecessor's experience and learn from the essence, can we observe today from a higher level, can our fashion design have a solider and deeper root and can the native fashion design be presented in the gallery of world fashion with a unique and fresh Chinese style.

\section{REFERENCES}

[1] Zhao Xiang. Application of Chinese Elements in International Brand Advertising under Cross-cultural Background. Master Dissertation of Wuhan Textile University. 2011: 8.

[2] TangYong. Application of Traditional Chinese Elements in Modern Package Design. Journal of Guilin Normal College, 2008, (12): 115.

[3] Liu Tianyong, Wang Peina. Nation, Fashion and Design-National Costume Elements and Fashion Design. Chemical Industry Press. Beijing, 2010: 173.

[4] Yang Yuan, He Xingliang. Studies on National Costume and Cultural Heritage-2004 Annual Conference Proceedings of Chinese Association of Ethnology. Yunnan University Press. Kunming, 2006: 28.

[5] Christine Tsui. China Fashion: Conversations with Designers. China Textile Press.Beijing, 2014.3. 